\begin{tabular}{|c|c|}
\hline & Volume \& Issues Obtainable at The Women University Multan \\
\hline
\end{tabular}

\title{
Socioeconomic Classes of University Students in Pakistan as Predictors of their Personality Traits: A Case Study
}

\author{
Rafaquat Ali ${ }^{1}$, Furrukh Bashir ${ }^{2}$, Rashid Ahmad ${ }^{3}$
}

${ }^{1}$ Assistant Professor, Department of Education, The Islamia University of Bahawalpur, Bahawalnagar Campus

2 Assistant Professor, School of Economics, Bahauddin Zakariya University, Multan

${ }^{3}$ Assistant Professor, School of Economics, Bahauddin Zakariya University, Multan

ARTICLE DETAILS ABSTRACT

\section{History:}

Received:

August 16, 2021

Review:

October 20, 2021

Accepted: $\quad$ November 08,2021

Available Online:November 08,2021

\section{Keywords:}

Socioeconomic Class immobility,

Personality immobility, Academic

Performance, Five Factor

Personality Model, Middle Upper

Socioeconomic Class, Lower

Socioeconomic Class.

\section{DOI:}

10.52700/assap.v2i2.51
The current study was heading for determining the impact of Pakistani university students' socioeconomic classes on their personality traits. Demographic and personality questionnaires were filled by available university students online. The stepwise regression technique facilitated to generate of regression models to define the impacts of different socioeconomic classes on students' different personality traits. Different regression models highlighted the significant negative impacts of the middle upper socioeconomic class on Agreeableness, Extraversion, and Neuroticism personality traits. The lower socioeconomic class was found to have a positive impact on only one personality sub-trait self-discipline. Whereas, the upper lower socioeconomic class caused positive impacts on students' trust sub-trait, Conscientiousness trait and negative impact on excitement seeking sub-trait of personality. The importance of these impacts of socioeconomic classes on different personality traits and the possible implications are discussed with respect to university students' academic performance and academic behavior.

(C) 2021 The Authors, Published by WUM. This is an Open Access Article under the Creative Common Attribution Non Commercial 4.0

Corresponding author's email address: furrukh@bzu.edu.pk

\section{Introduction}

Every human life activity whether cognitive, emotional, educational, social and personal, family or societal can be elaborated by interpretation of human personality types (Kankaraš, 2017). In this way, the personality construct overarches all aspects of human life. Accordingly, the construct of personality has two objectives: first, to identify stable 
observable patterns of behaviors among humans, and the second; to use these identified stable patterns to predict differences in other human attributes (Chamorro-Premuzic \& Furnham, 2005). In human history, these two objectives kept academicians, philosophers, and even laymen absorbed, and as a result, the different elements and models of personality existed in different periods of human history. For example; in ancient astrology, Hippocrates' concepts of human body fluids were interpreted into four personality types, Ernst Kretschmer's morphological theory, Sheldon's stereotype personality, psychosocial personality theories, psychobiological theories and personality trait models (Kavirayani, 2018). These multidisciplinary approaches ended in different multidimensional models of personality that bridged factors ranging from human biology to human history to outline the complex nature of human personality (Barenbaum \& Winter, 2008). Among these approaches and perspectives, the most imminent is psychoanalytic, humanistic, traits and socialcognitive(Cherry, 2019). Consequently, an era of chaos prevailed in the field of personality over the centuries. The different models of personality were short of integrating theories, and these models have different scales and labels for different personality sub-elements existed till the late 1980s (John et al., 2008).

In recent years, the most often used framework of personality is the personality trait framework (Vazire, 2014). Although the personality models of Carl Gustav Jung, Alfred Adler, and Ernst Kretschmer constituted traits at some level, the traits they included were limited in number, vague and their personality models did not cover all traits of humans (Dumont, 2010). However, the debate about the basic elements of personality and what constitutes personality ended with the introduction of five factor personality model (Crozier, 1997; McCrae \& Costa, 2008). The model of five factor personality traits is the present-day personality model (McCrae \& Costa, 2008).

Nowadays, the OCEAN acronym for five traits of personality; Openness, Conscientiousness, Extraversion, Agreeableness, and Neuroticism is widely used (Maltby et al., 2017). These personality traits are internal rather than contextual and these affect all other aspects of human behavior (Chamorro-Premuzic \& Furnham, 2005). Openness is a predictor of aesthetic sense, artistic and creative behavior (Diener et al., 2018). Individuals high on this trait are curious, untraditional, divergent and independent thinkers, they visualize new and unconventional solutions to problems and experience new solutions(Maltby et al., 2017). The Conscientiousness trait is related to an order, planning, commitment, persistence, dedication and high motivation (Soto, 2018). It shows how much an individual is focused, selfregulated, self-organized, determined and careful(Maltby et al., 2017). Conscientiousness trait shows preference to plan things and desire to achieve professionalism in jobs or tasks at hand (Maltby et al., 2017).

The Extraversion trait narrates a talkative, and companionable personality (Diener et al., 2018). It measures socialization, friendliness, celebrating tendency, and frankness behavior in individuals (Maltby et al., 2017). Agreeableness trait reflects human kind heartedness, affectionate behavior, care for others, trusting nature, cooperation and helpfulness(Maltby et al., 2017). People low in Agreeableness show rudeness, unkindness, apathetic behavior (Diener et al., 2018)The last trait Neuroticism measures negative emotions such as anxiety, sadness, mood swings, lack of resilience and lack of calmness (Soto, 2018). Low scores on this trait indicate emotional stability, personal adjustment, emotional calmness, and ideal emotional characteristics and emotional regulation (Maltby et al., 2017). Furthermore, each one of these five traits has sub-scales and facets (Maltby et al., 2017). 
Unquestionably, these five traits cover different dimensions of human behavior in personal, social and workstation situations. These traits affect human abilities and capacities during engagement in all kinds of tasks. The big five personality trait, Neuroticism is positively linked to poor self-rated health and negatively associated with life satisfaction. Contrariwise, Conscientiousness and Extraversion are positively related to better self-reported health and life satisfaction (Heilmann et al., 2021). Similarly, subjective vitality is readiness and inner energy for purposeful activity, and subjective vitality is also associated with big five factor personality traits (Engin Deniz \& Ahmet Satici, 2017). Personality traits Extraversion, Agreeableness, and Openness are positively associated with subjective vitality as compared to Neuroticism that is negatively associated with subjective vitality (Engin Deniz \& Ahmet Satici, 2017). Similarly, important attributes helpful at the workplace such as the ability to work independently, positive interactions with colleagues, boss and customers, diligence, handwork, novelty, etc. are related to the big five personality traits. Conscientiousness and Agreeableness traits are indispensable for success in a wide range of different jobs, to have much experience at one workplace, and achieving success in training courses at a job(Sackett \& Walmsley, 2014).

In this way, the big five personality traits forecast a number of human life outcomes. The social outcomes depend on Extraversion, the pro-social outcomes are defined by Agreeableness, the health and achievements are determined by Conscientiousness, the creative and intellectual outcomes of life are related with Openness, whereas subjective wellbeing has negative and low satisfaction in life has positive relationships with Neuroticism (Joshanloo \& Afshari, 2011; Soto, 2018).

Likewise, education is an important life activity and a life outcome. Openness personality trait has a sub-facet of curiosity, artistic interest and intelligence; these sub-facets are more linked to the knowledge accumulation nature of the students and this nature motivates students to learn beyond their cognitive abilities(Rolfhus \& Ackerman, 1999). Whereas, Extraversion trait has a negative impact on academic performance (Rolfhus \& Ackerman, 1999; Zuffianò et al., 2013) because highly Extraversion students might spend more time in social activities, such as partying and may spend lesser time in their study (Rolfhus \& Ackerman, 1999). Poropat (2009) found traits of Agreeableness, Conscientiousness and Openness to having significant positive relationships with students' academic performance. On the other hand, neurotic characteristics such as restlessness and anxiousness are associated negatively with students' academic achievements (Komarraju et al., 2011; Rosander \& Bäckström, 2012). Furthermore, students' information processing strategies are associated with their personality traits. For example, the use of memorization strategies is associated positively with Conscientiousness, Agreeableness and Neuroticism traits(Vermetten et al., 2001).Similarly, the students' behaviours to regulate their learning depend on their personality traits (Donche et al., 2013; Vermetten et al., 2001). However, among different personality traits, Conscientiousness trait is the most important predictor of students' academic performance (Andersen et al., 2020; Furnham et al., 2009) because it is related to sub-traits essential for academic achievements such as concentration, planning and dedication (Komarraju et al., 2011). Arguably, the relationships of different aspects of schooling with these five traits of personality vary with years of schooling, age, level of education (Andersen et al., 2020), and nature of the subject or the discipline (Brandt et al., 2020). 
Apart from the impacts of personality traits on students' academic behavior and academic performance, socioeconomic backgrounds as well affect students' academic performance (Ali et al., 2019; Yang \& Gustafsson, 2004). In literature, socioeconomic class (SEC) is commonly and consistently used to explain and elaborate inequalities in honors, controls and powers on economic resources within a society (American Psychological Association, 2019). SEC is the symbol of the social position of an individual in a society about income, profession and educational qualification (Rothstein, 2010). Socioeconomic discrimination or exclusion is the core agenda of education policies in developing and developed countries, though, different education systems safeguard social and economic inequalities within society (Yuxiao \& Chao, 2017). The selection of school, home environment, parents' involvement in child education, and students' learning outcomes depend on parents' SEC (Altschul, 2012; Eleftheria \& Tim, 2007). Although, SEC is the significant predictor of students' academic performance, however, the parental education among different indicators of SEC is a substantial predictor of students' performance (Farooq et al., 2011). Because of the lack of cognitive, technological and financial resources, the students of low SEC fail to apply elaboration strategies, and mostly they use memorization strategies as compared to the high SEC students whose deep cognitive processing strategies (Ali \& Bakar, 2019). The reason for the poor academic performance of low SEC students is the use of memorization strategies (Ali et al., 2019). Although exceptions are there, the students of low socioeconomic backgrounds taught in high quality instructional environments achieved lower grades (Rothstein, 2010).

The impact of SECs on students' personality traits is logical because the development of personality depends on home, school and neighborhood or community environment (Strickhouser \& Sutin, 2020). The impacts of SECs on child psychology are substantial (Bucciol et al., 2014). Therefore, the SECs correlate with scores on different personality traits (Gottfried et al., 2003; Jonassaint et al., 2011). The probability is there that children of higher SEC will be more patient, altruistic, and less risk taking and have high IQ scores (Deckers et $a l ., 2015)$. The parental SEC and the students' cognitive intelligence correlate with students' personality traits of Extraversion, emotional stability, Agreeableness, Conscientiousness, and intellect or Openness(Cheng \& Furnham, 2014). The individuals scoring high on Openness and Conscientiousness traits can be most likely from higher socioeconomic backgrounds, whereas individuals scoring high on Extraversion, Agreeableness and Neuroticism traits might be from the lower socioeconomic background (Bucciol et al., 2014).

The indicators of SEC; parents' education, occupation and income have significant relationships with children's personality traits. However, these relationships might have different implications. For example, the parent's income and their superior occupational status can have a positive correlation with children's Extraversion trait, and these two can have a negative correlation with Neuroticism(Hughes et al., 2021), though, parents' income can have a negative correlation with Agreeableness trait (Hughes et al., 2021). The impact of these indicators on personality traits might be lifelong (Hughes et al., 2021; Strickhouser \& Sutin, 2020). Similar to the concept of class immobility, the SEC can result in personality immobility. The parental personalities developed as a result of their SECs are copied in their children. Especially, the mothers of higher SEC transfer their tolerance, patience and IQ to their children (Deckers et al., 2015). In this way, there is massive evidence that suggests that SECs can predict and control the personality development of children (Gottfried et al., 2003). 


\section{Statement of the Problem}

The above discussion culminates in the concept that students' personality traits and SECs play important roles in their education. The personality and SECs also appear to be correlated. Arguably, the strength and nature of the relationships of different SECs with students' learning achievements or educational outcomes depend on school systems, examination systems, and whether schools are centralized or decentralized, its finance, cultural and social fabric of the society and systems of students' intake into different educational tracks, hence, these relationships vary from country to country(Yang \& Gustafsson, 2004). Most of the research on these relationships is carried out in the Western context, and very little evidence is found in the context of Asian countries and especially in the context of Pakistan. The related literature about these relationships from Pakistan is scarce. There is a lack of substantial evidence that explains how personality traits and SECs are correlated in Pakistani culture, society and social setup. Hence the current study measured the prediction role of SECs in determining the university students' personality traits. In this regard, the following conceptual framework is used (Figure 1).

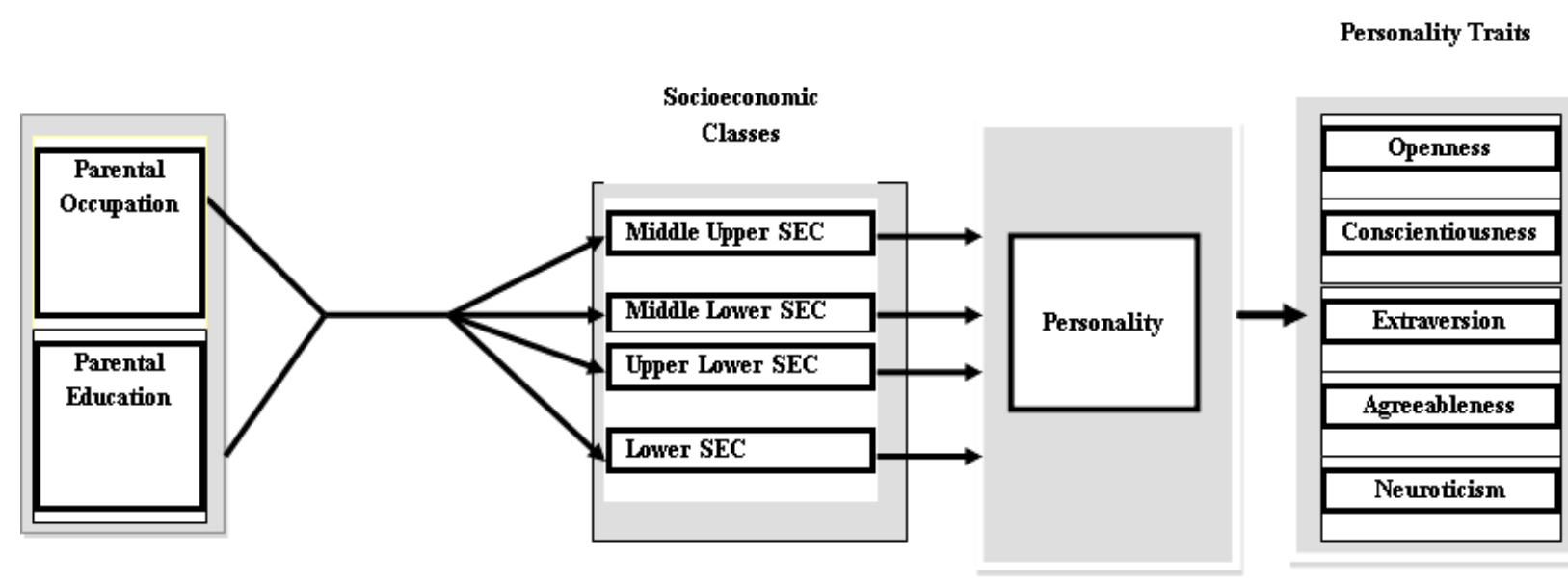

Figure 1: Conceptual Framework

\subsection{Objectives of the Study}

The study was designed to obtain the following objectives:

1. To measure the impact of students' SECs on their Openness trait of personality.

2. To measure the impact of students' SECs on their Conscientiousness trait of personality.

3. To measure the impact of students' SECs on their Extraversion trait of personality.

4. To measure the impact of students' SECs on their Agreeableness trait of personality.

5. To measure the impact of students' SECs on their Neuroticism trait of personality.

\subsection{Hypotheses of the Study}

The following hypotheses were assumed to acquire the above objectives:

1. There will be no significant impact of students' SECs on their Openness trait of personality. 
2. There will be no significant impact of students' SECs on their Conscientiousness trait of personality.

3. There will be no significant impact of students' SECs on their Extraversion trait of personality.

4. There will be no significant impact of students' SECs on their Agreeableness trait of personality.

5. There will be no significant impact of students' SECs on their Neuroticism trait of personality.

\subsection{Population and Sample}

The Pakistani university students were the population of the study. The Islamia University of Bahawalpur, Bahawalnagar campus was the cluster chosen purposefully and conveniently from three campuses of the Islamia University of Bahawalpur for data collection. Within the cluster of Bahawalnagar campus, the information was collected from volunteer students through Google forms. After screening for missing data, and deletion of extreme cases, the 414 students' online filled forms were selected for data analysis.

\section{Data Collection Measures}

The socioeconomic status is usually classified into upper, middle and lower SECs in most countries (Hofstede et al., 2010). Because the SEC is a latent variable, therefore, different observable indicators such as; income, household consumption, education and employment are used to calculate SEC(Australian Bureau of Statistics, 2011). Among these different indicators of SEC, the three indicators education, occupation and income are most commonly used to measure the SEC (Currie et al., 1997). However, the most stable component of SEC is parental education because it remains almost the same from an early age to old age (Sirin, 2005).

In this study, the composite indicator of SEC was calculated by the addition of scores of students' parental occupation and education. The parental income was not included in the calculation of students' SEC because parents' income is more preferable to use in health inequalities, while educational and psychological developmental inequalities mostly depend on parents' occupation and education (Darin-Mattsson et al., 2017). Additionally, the respondents in this study were university students who were unaware of the actual income of their parents. As a result, the indicators of parents' occupation and education were used to calculate students' SECs. The information provided by students about their parental occupation and education was scored according to the key proposed in Kuppuswamy's Socioeconomic Status Scale (Sharma, 2017). In this scale, all educational qualifications are divided into seven categories (ranging from illiteracy to post-graduation or professional education. Whereas, the different occupations are also divided into seven categories (ranging from unemployed to highly professional/ occupational background). The accumulated scores of parental occupations and educational qualifications fall into four SECs; Lower SEC, Upper Lower SEC, Middle Lower SEC, and Middle Upper SEC.

For personality measurement, 60 items of five factor personality model measuring five traits of personality; namely Conscientiousness, Openness, Agreeableness, Extraversion and Neuroticism were selected from the website of International Personality Item Pool. Following the categorization of Johnson (2014), the five personality traits further consisted sub-facets or sub traits (Conscientiousness $=$ Cautiousness, Self-discipline, Achievement Striving; 
Agreeableness = Trust, Altruism, Sympathy; Extraversion = Assertiveness, Friendliness, Excitement Seeking; Openness = Emotionality, Intellect, Artistic Interests; Neuroticism = Depression, Anxiety, Anger).

\section{Data Analysis}

The researchers used SPSS software for data analysis. The composite variable of SEC consisted of four categories. Therefore, these four categorical variables or four SECs were further transformed into dummy variables. Hence, each SEC has two values (1 and 0). The simple linear regression (Stepwise) was used to see the prediction role of each SEC in the prediction of each personality trait. The significant values and indices of linear regression (stepwise) were used in the regression model equation to elucidate the importance of SECs in the prediction of students' five factor personality traits.

\section{Results}

Table No. 1 shows the relationships of different sub-traits, traits of personality and students' SECs. There are significant positive relationships among three sub-traits of Neuroticism; anxiety, anger, depression. As well, these three sub-traits of Neuroticism have significant positive relationships with the overall Neuroticism trait. In the case of the Extraversion trait, the sub-traits of this trait were interrelated positively; however, significant relationships were between friendliness and assertiveness, and excitement seeking and assertiveness. The relationship between friendliness and excitement seeking was positive but insignificant. However, these three sub-traits of Extraversion have significant and positive relationships with the main trait Extraversion. Likewise, there are positive relationships among the subtraits of Openness to experiences such as artistic interest, emotionality, and intellect. Furthermore, these three sub-traits of Openness have significant and positive relationships with the overall chief trait of Openness to experience.

Moreover, the sub-traits of Agreeableness; trust, altruism, and sympathy and the overall trait of Agreeableness have positive and significant interrelationships. The sub-traits of Conscientiousness trait such as achievement striving, self-discipline and cautiousness have a positive significant interrelationship with each other and with the Conscientiousness trait. Among five factor main traits, the Neuroticism trait has significant negative relationships with Openness and consciousness traits. Whereas the Extraversion trait has positive relationships with Openness and Agreeableness, and the Openness trait has significant positive relationships with Agreeableness and consciousness.

Table 1: Interrelationships of Personality Sub-Traits, Traits and Socioeconomic Classes

\begin{tabular}{|c|c|c|c|c|c|c|c|c|c|c|c|c|c|c|c|c|c|c|c|c|c|c|c|c|}
\hline & & 1 & 2 & 3 & 4 & 5 & 6 & 7 & 8 & 9 & 10 & 11 & 12 & 13 & 14 & 15 & 16 & 17 & 18 & 19 & 20 & 21 & 22 & 23 \\
\hline 1 & Anxiety & 1 & & & & & & & & & & & & & & & & & & & & & & \\
\hline$\underline{2}$ & Anger & $.339 * *$ & 1 & & & & & & & & & & & & & & & & & & & & & \\
\hline 3 & Depression & $.295 * *$ & $.304 *$ & & & & & & & & & & & & & & & & & & & & & \\
\hline 4 & Friendliness & -.056 & $\begin{array}{l}- \\
.143 *\end{array}$ & $\begin{array}{l}- \\
* .181 *\end{array}$ & 1 & & & & & & & & & & & & & & & & & & & \\
\hline 5 & Assertiveness & $.101 *$ & -.061 & $-.110^{*}$ & $* .134 * *$ & & & & & & & & & & & & & & & & & & & \\
\hline 6 & $\begin{array}{l}\text { Excitement } \\
\text { Seeking }\end{array}$ & $.333^{* * *}$ & $.265^{*}$ & $* .228 *=$ & $* .018$ & & & & & & & & & & & & & & & & & & & \\
\hline
\end{tabular}




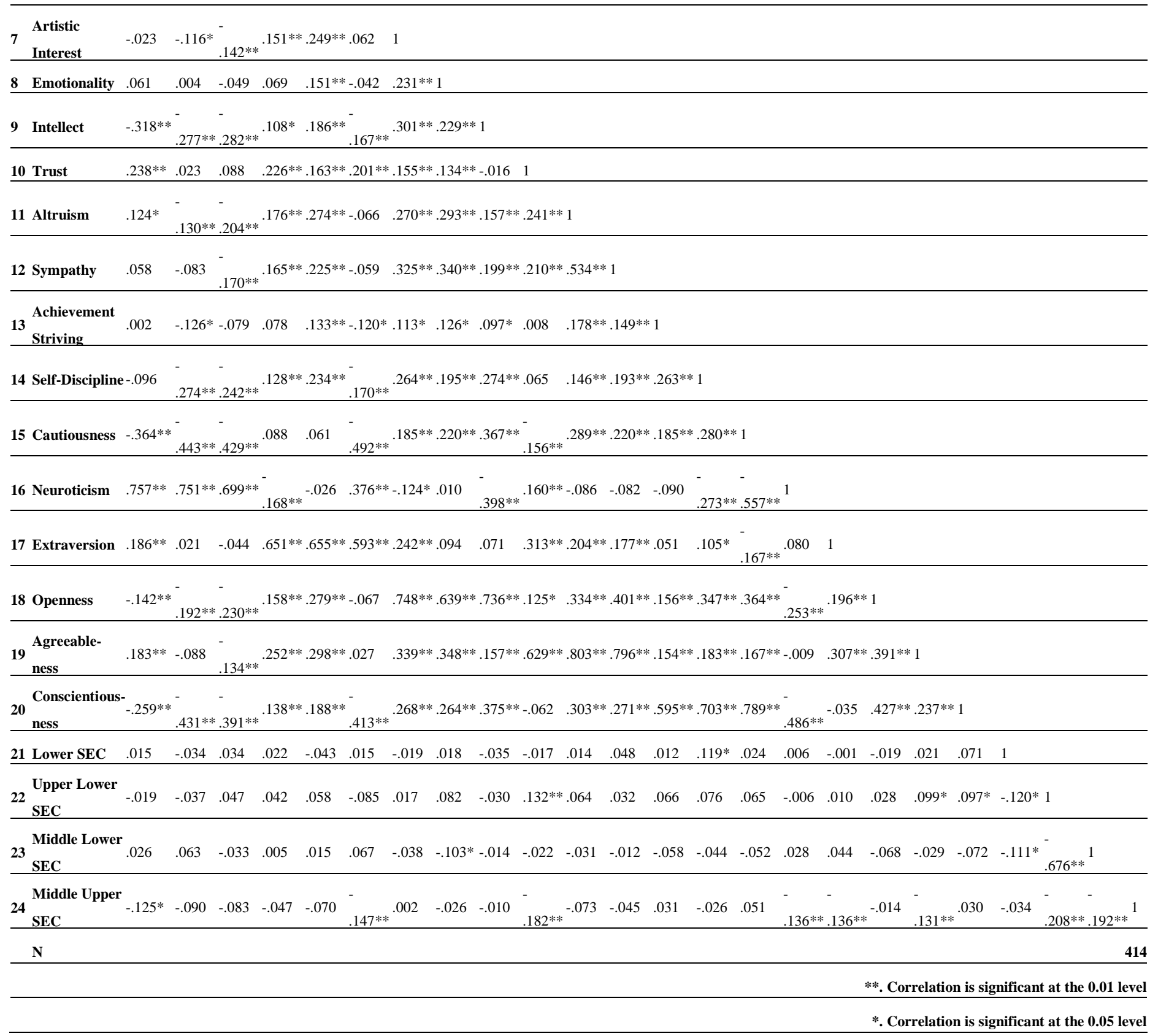

Furthermore, the agreeableness trait has significant positive relationships with Conscientiousness. In the case of interrelationships of different SECs and five factor personality traits and sub-traits, the lower SEC has a significant positive relationship only with self-discipline which is a sub-trait of Conscientiousness. A significant positive relationship exists between the upper lower SEC and trust which is a sub-trait of Agreeableness.

Correspondingly, there is a significant positive association between upper lower SEC and the Agreeableness trait. Although, upper lower SEC has no significant relationship with any subtrait of Conscientiousness, however, it has a very small positive relationship with the main trait Conscientiousness. Whereas, the middle lower SEC has a significant but negative relationship with emotionality, a sub-trait of Openness. The correlation analysis revealed that middle upper SEC has significant negative relationships with anxiety (sub-trait of 
Neuroticism), excitement seeking (sub-trait of Extraversion), trust (sub-trait of Agreeableness), traits of Neuroticism, Extraversion and Agreeableness.

The significant relationships among different SECs and personality traits were further analyzed to establish the importance of different SECs in the prediction of different personality traits. Table No. 2 shows the role of different SECs in the prediction of different sub-traits and traits of personality. The middle upper socioeconomic has appeared to impact and predict most of the personality traits and sub-traits.

Table No. 2 shows that lower SEC can significantly predict the sub-trait self-discipline in university students. The self-discipline sub-trait is a component of the Conscientiousness trait. In model 1, the presence of lower SEC can cause an increase of 2.357 units in students' self-discipline sub-trait. The lower SEC significantly explained the 1.2 percent variance in students' self-discipline sub-trait. The rest of the three SECs have failed to cause any significant increase or decrease in self-discipline which is a sub-trait Conscientiousness.

With respect to the impacts of different SECs on students' trust sub-trait, there were two models generated. It is evident in Model 2, that the middle upper SEC has been entered and the rest of the three SECs are excluded from the model. The middle upper SEC has significantly explained a 3.1 percent variance in students' trust sub-trait. The trust sub-trait is an element of the Agreeableness trait of personality. The presence of middle upper SEC can result in a significant decrease of 2.279 units in the sub-trait of trust.

However, in Model 3, the middle upper and upper lower SECs have been entered and the other two SECs, the lower and middle lower SECs have been excluded from the model. Both SECs; the middle upper and upper lower explained a 3.8 percent variance in students' trust sub-trait of Agreeableness, though these two have opposite impacts on trust sub-trait. The presence of middle upper SEC can cause a decrease of 2.022 units in trust scores, as compared to upper lower SEC that can cause an increase of 0.574 units in trust sub-trait.

In model 4, the middle upper SEC has significantly explained a 1.5 percent variance in the Agreeableness trait. The remaining three SECs are excluded from the model because of their insignificant impacts on the Agreeableness trait. The middle upper SEC can cause a decrease in Agreeableness trait up to 03.877 units.

The results of model 5 show that only the upper lower SEC among four SECs has been able to cause a significant impact on the personality trait of Conscientiousness. The upper lower SEC explains 0.7 percent variance in the Conscientiousness trait and its presence can cause an increase of 1.219 units in the Conscientiousness trait.

Model 6 confirms that middle lower SEC can explain a very small amount of variance in emotionality traits. It explains a 0.8 percent variance in emotionality sub-trait, and its presence can result in a 0.555 unit decrease in emotionality. The remaining three SECs do not show any significant impact on emotionality sub-trait. Likewise, Model 7 shows that the middle upper SEC has a significant negative impact on anxiety. The middle upper SEC contributed a variance of 1.3 percent in anxiety a sub-trait of Neuroticism. The middle upper SEC cause 1.923 units decrease in anxiety. 
Table 2: Regression Models

\begin{tabular}{|c|c|c|c|c|c|c|c|c|}
\hline \multirow{2}{*}{$\begin{array}{l}\text { Model } \\
\text { Nos. }\end{array}$} & \multicolumn{2}{|c|}{ Variables } & \multirow{2}{*}{$\begin{array}{c}\text { Dependent } \\
\text { variable }\end{array}$} & \multirow{2}{*}{$\begin{array}{c}\text { Adjusted } \\
\mathbf{R}^{2}\end{array}$} & \multicolumn{4}{|c|}{ Coefficients } \\
\hline & Entered & Excluded & & & Model & Beta & $\begin{array}{c}\text { Std. } \\
\text { Error }\end{array}$ & Sig. \\
\hline & & & & & Constant & 13.643 & 0.135 & 0.000 \\
\hline \multirow[t]{3}{*}{1} & L-SEC & UL-SEC & Self-discipline & 0.012 & L-SEC & 2.357 & 0.971 & 0.016 \\
\hline & & ML-SEC & & & & & & \\
\hline & & MU-SEC & & & & & & \\
\hline \multirow[t]{3}{*}{2} & MU-SEC & L-SEC & Trust & 0.031 & Constant & 13.974 & 0.143 & 0.000 \\
\hline & & UL-SEC & & & MU-SEC & -2.279 & 0.607 & 0.000 \\
\hline & & ML-SEC & & & & & & \\
\hline \multirow[t]{3}{*}{3} & MU-SEC & L-SEC & Trust & 0.038 & Constant & 13.718 & 0.192 & 0.000 \\
\hline & UL-SEC & ML-SEC & & & MU-SEC & -2.022 & 0.618 & 0.001 \\
\hline & & & & & UL-SEC & 0.574 & 0.286 & 0.046 \\
\hline \multirow[t]{3}{*}{4} & MU-SEC & L-SEC & Agreeableness & 0.015 & Constant & 45.182 & 0.341 & 0.000 \\
\hline & & UL-SEC & & & MU-SEC & -3.877 & 1.446 & 0.008 \\
\hline & & ML-SEC & & & & & & \\
\hline \multirow[t]{3}{*}{5} & UL-SEC & L-SEC & Conscientiousness & 0.007 & Constant & 39.833 & 0.403 & 0.000 \\
\hline & & ML-SEC & & & UL-SEC & 1.219 & 0.619 & 0.05 \\
\hline & & MU-SEC & & & & & & \\
\hline \multirow[t]{3}{*}{6} & ML-SEC & L-SEC & Emotionality & 0.008 & Constant & 13.882 & 0.164 & 0.000 \\
\hline & & UL-SEC & & & ML-SEC & -0.555 & 0.265 & 0.037 \\
\hline & & MU-SEC & & & & & & \\
\hline \multirow[t]{3}{*}{7} & MU-SEC & L-SEC & Anxiety & 0.013 & Constant & 14.097 & 0.177 & 0.000 \\
\hline & & UL-SEC & & & MU-SEC & -1.923 & 0.75 & 0.011 \\
\hline & & ML-SEC & & & & & & \\
\hline \multirow[t]{3}{*}{8} & MU-SEC & L-SEC & Excitement Seeking & 0.019 & Constant & 12.164 & 0.145 & 0.000 \\
\hline & & UL-SEC & & & MU-SEC & -1.859 & 0.617 & 0.003 \\
\hline & & ML-SEC & & & & & & \\
\hline \multirow[t]{3}{*}{9} & MU-SEC & L-SEC & Excitement Seeking & 0.031 & Constant & 12.481 & 0.195 & 0.000 \\
\hline & UL-SEC & ML-SEC & & & MU-SEC & -2.177 & 0.627 & 0.001 \\
\hline & & & & & UL-SEC & -0.71 & 0.291 & 0.015 \\
\hline \multirow[t]{3}{*}{10} & MU-SEC & L-SEC & Neuroticism & 0.016 & Constant & 35.939 & 0.37 & 0.000 \\
\hline & & UL-SEC & & & MU-SEC & -4.373 & 1.571 & 0.006 \\
\hline & & ML-SEC & & & & & & \\
\hline \multirow[t]{2}{*}{11} & MU-SEC & L-SEC & Extraversion & 0.016 & Constant & 38.98 & 0.289 & 0.000 \\
\hline & & UL-SEC & & & MU-SEC & -3.414 & 1.227 & 0.006 \\
\hline
\end{tabular}

L-SEC = Lower Socioeconomic Class, UL-SEC = Upper Lower Socioeconomic Class, ML-SEC = Middle Lower Socioeconomic Class, MU-SEC = Middle Upper Socioeconomic Class

In stepwise regression, models 8 and 9have affirmed the impacts of middle upper and upper lower SECs on excitement seeking sub-trait. In model 8, the middle upper SEC is entered in the regression model while the other three SECs are excluded from the model. The middle upper SEC explains a 1.9 percent variance in excitement seeking sub-trait of Extraversion. Its impact is negative and it can decrease excitement seeking up to 1.859 units. However, model 
9 explains the variance of excitement seeking sub-trait about middle upper and upper lower SECs. The two SECs produce a negative impact on excitement seeking sub-trait in students (middle upper $\mathrm{B}=-2.177$, upper lower $\mathrm{B}=-0.71$ ). However, the negative impact of the middle upper SEC is larger than the upper lower SEC. The combination of both SECs contributes 3.1 percent variance in excitement seeking sub-trait.

In the case of Neuroticism personality trait, only middle upper SEC has significant impact (Model 10). In Model 10, the middle upper SEC has a negative impact on Neuroticism trait $(\mathrm{B}=-4.373)$.

The Middle upper SEC explained a 1.6 percent variance in Neuroticism. Likewise, the middle upper SEC displays a significant negative effect on Extraversion personality trait (Model 11). The remaining three SECs lack significant impact on the Extraversion trait; therefore, these are excluded from Model 11. The middle upper SEC explains a 1.6 percent variance in the Extraversion trait. The presence of middle upper SEC might decrease the Extraversion trait up to 3.414 units. The probable increase or decrease in different personality traits and subtraits because of the presence of different SECs is illustrated in Figure 2. The most obvious impact is of the middle upper SEC that appears capable of impacting most of the personality traits or sub-traits. The Neuroticism personality trait and its sub-trait anxiety, both are related to students' poor academic performance and emotional instability. The middle upper SEC causes a significant massive decrease in students' Neuroticism trait.

Equally, anxiety can also limit students' effort and desire to succeed, and this sub-trait also decreases with the presence of middle upper SEC. Similarly, the Extraversion trait and its sub-trait excitement seeking decrease with the presence of middle upper SEC. Furthermore, the Agreeableness trait and its sub-trait trust decrease with the presence of middle upper SEC. The second most important SEC that can impact different personality traits and sub-traits is upper lower SEC, which causes an increase in trust sub-trait and Conscientiousness trait and a decrease in excitement seeking sub-trait (Extraversion). 


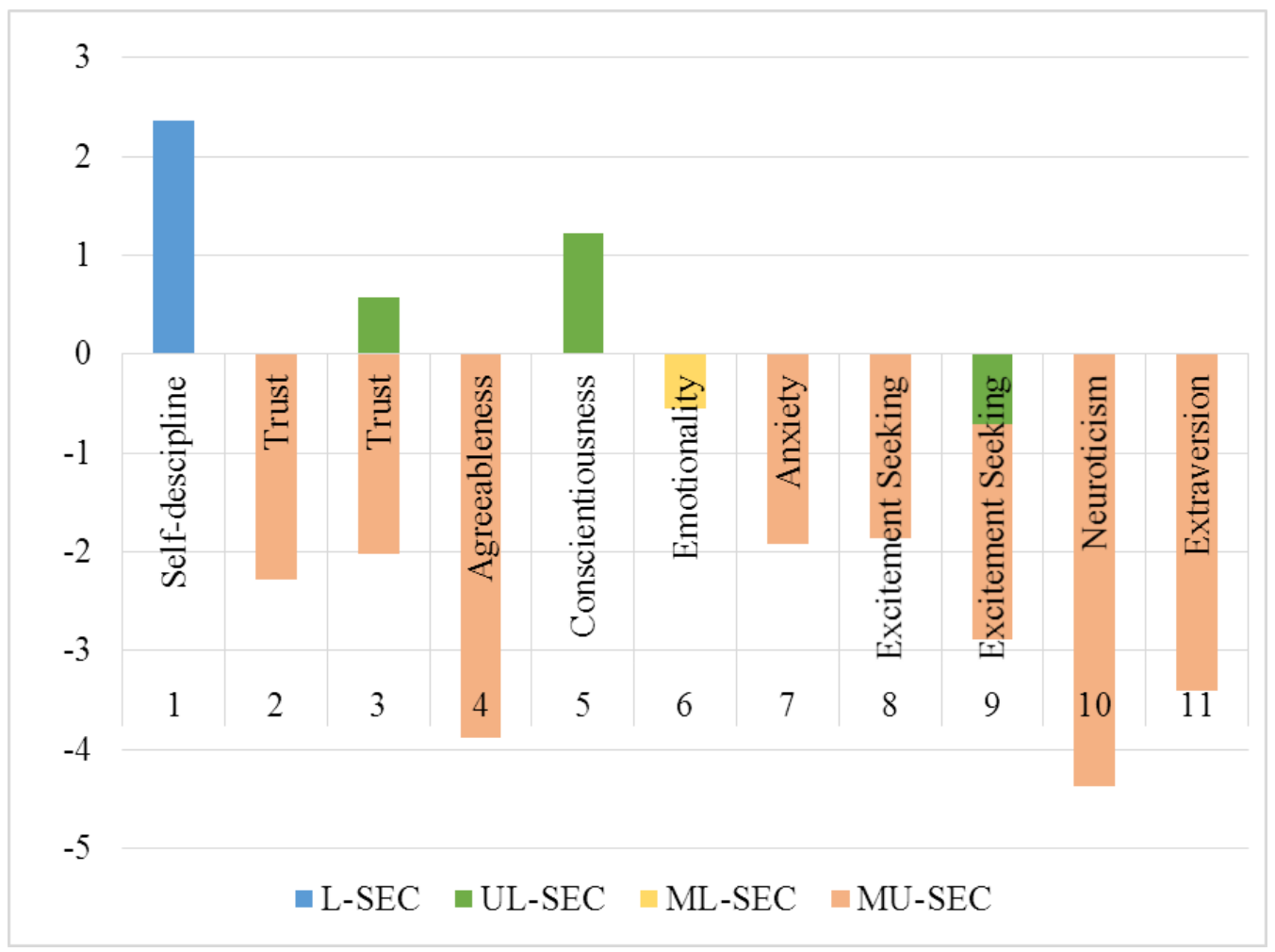

Figure 2: Relative Prediction of Increase or Decrease in Personality traits by SECs

\section{Discussion}

The results of this study show that the middle upper SEC is the most important with respect to impacts on students' personality traits. The existence of middle upper SEC has a significant negative impact on students' trust sub-trait and Agreeableness trait, anxiety subtrait and Neuroticism trait, excitement seeking sub-trait and Extraversion trait. Even though the middle lower SEC has a significant negative impact on emotionality sub-trait, however, this impact is so small that it does not appear in the Openness to experience trait. In the same manner, the upper lower SEC has a significant negative effect on excitement seeking subtrait, and a significant positive effect on trust sub-trait, however, these impacts are not large enough to appear in Extraversion and Agreeableness traits. Contrary to aforesaid scenarios, there is no significant impact of upper lower SEC on any one of the three sub-traits of Conscientiousness; cautiousness, self-discipline, and achievement striving, however, this SEC has a significant positive impact on students' overall Conscientiousness scores. The impact of lower SEC is not obvious in the overall Conscientiousness trait, though; the lower SEC has a positive impact on self-discipline sub-trait.

The negative relationship of Neuroticism trait with only students of middle upper SEC has reinforced the evidence that children of poor and less superior socioeconomic families have more negative emotions as compared with children of superior SEC(Brooks-Gunn \& Duncan, 1997). Furthermore, the negative relationship of Neuroticism and its sub-trait anxiety with middle upper SEC is aligned to the consistent evidence in the literature. For the reason that the higher SECs are associated with higher academic grades, whereas, anxiety and Neuroticism are associated with poor academic performance(Komarraju et al., 2011). 
Equally, the presence of higher scores of Neuroticism, Extraversion and Agreeableness in individuals of low SECs is acknowledged in literature (Bucciol et al., 2014). Similarly, this study found that as compared to lower, the upper lower and middle lower SECs, the middle upper SEC is capable to cause a significant substantial decrease in Extraversion, Neuroticism and Openness to experience traits. As well, this study establishes that less superior SECs have positive relationships with Agreeableness and Extraversion traits. Evidence exists that these traits are negatively associated with the student's performance (Brandt et al., 2020). It is reasonable that these traits have a significant negative association with superior SECs because students of superior SECs have higher academic achievements (Ali et al., 2019; Yang \& Gustafsson, 2004), and the students of higher SEC have lower Neuroticism (Jonassaint et al., 2011).

Unpredictably, the upper lower and lower SECs are found positively associated with subtraits and traits of Conscientiousness and Agreeableness. These findings are inconsistent to some extent with the literature. The probable reason is that the students of upper lower and lower SECs have great motivation and commitment for their study and have considerable self-regulation of their learning as compared to students of superior or higher SECs. The recurrent findings have pointed out that the Conscientiousness traits a qualifier for academic success and academic performance (Furnham et al., 2009). However, the relationships of the Conscientiousness trait with academic performance depend on the nature of the discipline of the study. Certain subjects or disciplines of study have strong relationships with the conscientious trait(Brandt et al., 2020). Another explanation of the above apparent findings' inconsistencies to literature is that the sample of this study is university students. It is itself an extraordinary phenomenon that students of poor and less superior socioeconomic backgrounds have reached up to university education. Of course, these are not stereotyped students of less superior backgrounds. These are extraordinary students from less superior backgrounds who are greatly determined and motivated for their success in university education because higher education is the ladder to land in higher SEC and a key to SEC mobility (Hofstede et al., 2010).

Likewise, it is worth mentioning that the upper lower SEC is positively associated with trust a sub-trait of Agreeableness, however, the Agreeableness trait is found related to students' memorization behavior (Vermetten et al., 2001). Whereas, the memorization strategies are associated with poor academic performance (Albaili, 1998). Consequently, higher academic performance is normal in students of superior SEC, therefore, the presence of negative association of Agreeableness trait with students of superior SECs is understandable. In the case of the negative association of Extraversion trait and sub-trait excitement seeking with superior SEC, it is notable that relationships of Extraversion trait with higher academic performance are not consistent (Rolfhus \& Ackerman, 1999; Rosander \& Bäckström, 2012). Therefore, the negative relationship of Extraversion trait with students of superior SEC who are generally better performing students is justified to some extent.

\section{Recommendations}

The knowledge of human traits has helped categorize humans into different personality types and groups. In human history, these classifications have emerged as tools to predict and understand human behaviors in different contexts. In this regard, the contemporary five factor personality model defines human behavior with respect to five traits. These five traits have been found to impact human behaviors in all contexts of human life. In an educational 
context, the students' scores on these traits are found to be related to students' academic performance and academic behavior. However, the socioeconomic status that represents the social and economic position of people in any society with respect to their wealth, occupation and education has appeared to impact students' academic behavior, academic performance and personality traits. Nonetheless, these relationships vary with social, cultural and educational contexts. Therefore, the current study was heading for determining the impact of Pakistani university students' socioeconomic classes on their personality traits. Demographic and personality questionnaires were filled by available university students online. The stepwise regression technique facilitated to generation of regression models to define the impacts of different socioeconomic classes on students' different personality traits. Different regression models highlighted the significant negative impacts of the middle upper socioeconomic class on Agreeableness, Extraversion and Neuroticism personality traits. The lower socioeconomic class was found to have a positive impact on only one personality subtrait self-discipline. Whereas, the upper lower socioeconomic class caused positive impacts on students' trust sub-trait, Conscientiousness trait and negative impact on excitement seeking sub-trait of personality. The importance of these impacts of socioeconomic classes on different personality traits and the possible implications are discussed with respect to university students' academic performance and academic behavior.

From the above discussion, it is established that there are obvious impacts of SECs on students' personalities. Different SECs have different implications in personality development. Counseling and guidance are needed for students of all SECs. However, there should be appropriate screening to identify the nature of counseling and guidance needed for university students.

\section{References}

Albaili, M. A. (1998). Goal Orientations, Cognitive Strategies and Academic Achievement Among United Arab Emirates College Students[1]. Educational Psychology, 18(2), 195-203. doi:10.1080/0144341980180205

Ali, R., \& Bakar, A. (2019). The Probability to Memorize and Understand Textbook Information: Socioeconomic Class as the Predictor for Cognitive Processing Strategies in Pakistani Education System. Pakistan Journal of Social Sciences (PJSS), 39(1). Retrieved from http://pjss.bzu.edu.pk/website/journal/article/5ed01b676e874/page

Ali, R., Hussain, I., \& Rahmani, S. H. (2019). How Socioeconomic Classes Influence Academic Grades of Elementary School Students? Defining Mediation Role of School Backgrounds and Cognitive Processing Strategies. Journal of Educational Research (1027-9776), 22(2), 201227. Retrieved from http://jer.iub.edu.pk/journals/JER-Vol-22.No-2/15.pdf

Altschul, I. (2012). Linking Socioeconomic Status to the Academic Achievement of Mexican American Youth Through Parent Involvement in Education. Journal of the Society for Social Work and Research, 3(1), 13-30. doi:DOI:10.5243/jsswr.2012.2

American Psychological Association. (2019). Socioeconomic Status. Retrieved from https://www.apa.org/topics/socioeconomic-status

Andersen, S. C., Gensowski, M., Ludeke, S. G., \& John, O. P. (2020). A stable relationship between personality and academic performance from childhood through adolescence. An original study and replication in hundred-thousand-person samples. Journal of Personality, 88(5), 925-939. doi:https://doi.org/10.1111/jopy.12538

Australian Bureau of Statistics. (2011). Measures of Socioeconomic Status. Canberra : Australian Bureau of Statistics, 2011. Retrieved from https://trove.nla.gov.au/work/152545790

Barenbaum, N. B., \& Winter, D. G. (2008). History of Modern Personality Theory and Research. In O. P. John, R. W. Robins, \& L. A. Pervin (Eds.), Handbook of Personality, Theory and Research (Third Edition ed., pp. 3-28). New York: The Guilford Press. 
Brandt, N. D., Lechner, C. M., Tetzner, J., \& Rammstedt, B. (2020). Personality, cognitive ability, and academic performance: Differential associations across school subjects and school tracks. Journal of Personality, 88(2), 249-265. doi:https://doi.org/10.1111/jopy.12482

Brooks-Gunn, J., \& Duncan, G. J. (1997). The Effects of Poverty on Children. The Future of Children, 7(2), 55-71. doi:10.2307/1602387

Bucciol, A., Cavasso, B., \& Zarri, L. (2014). Social Status and Personality Traits. Department of Economics, University of Verona, Italy. Retrieved from http://dse.univr.it/home/workingpapers/wp2014n21.pdf (WP Number: 21)

Chamorro-Premuzic, T., \& Furnham, A. (2005). Personality Traits. In T. Chamorro-Premuzic \& A. Furnham (Eds.), Personality and Intellectual Competence. New Jersey: Lawrence Erlbaum Associates, Inc.

Cheng, H., \& Furnham, A. (2014). The Associations Between Parental Socio-Economic Conditions, Childhood Intelligence, Adult Personality Traits, Social Status and Mental Well-Being. Social Indicators Research, 117(2), 653-664. doi:10.1007/s11205-013-0364-1

Cherry, K. (2019). Theories Personality Psychology The 4 Major Personality Perspectives. Retrieved from https://www.verywellmind.com/personality-perspectives-2795950

Crozier, W. R. (1997). The reality of personality Individual Learners Personality Differences in Education. London: Routledge.

Currie, C. E., Elton, R. A., Todd, J., \& Platt, S. (1997). Indicators of socioeconomic status for adolescents: the WHO Health Behaviour in School-aged Children Survey. Health Education Research, 12(3), 385-397. doi:10.1093/her/12.3.385

Darin-Mattsson, A., Fors, S., \& Kåreholt, I. (2017). Different indicators of socioeconomic status and their relative importance as determinants of health in old age. International Journal for Equity in Health, 16(1), 173. doi:10.1186/s12939-017-0670-3

Deckers, T., Falk, A., Kosse, F., \& Schildberg-Hörisch, H. (2015). How Does Socio-Economic Status Shape a Child's Personality? Retrieved from Bonn, Germany: http://ftp.iza.org/dp8977.pdf

Diener, E., Lucas, R. E., \& Cummings, J. A. (2018). Personality Traits. In J. A. Cummings \& L. Sanders (Eds.), Introduction to Psychology Canada: University of Saskatchewan.

Donche, V., De Maeyer, S., Coertjens, L., Van Daal, T., \& Van Petegem, P. (2013). Differential use of learning strategies in first-year higher education: The impact of personality, academic motivation, and teaching strategies. British Journal of Educational Psychology, 83(2), 238251. doi:10.1111/bjep. 12016

Dumont, F. (2010). A History of Personality Psychology: Theory, Science, and Research from Hellenism to the Twenty-First Century. Cambridge: Cambridge University Press.

Eleftheria, N. G., \& Tim, U. (2007). Parental influences on student motivation, affect and academic behaviour: Introduction to the special issue. European Journal of Psychology of Education, 22(1), 3-6. doi:https://doi.org/10.1007/BF03173685

Engin Deniz, M., \& Ahmet Satici, S. (2017). The Relationships between Big Five Personality Traits and Subjective Vitality. Anales de Psicología, 33(2), 218-224. Retrieved from https://www.redalyc.org/articulo.oa? id=16750533002

Farooq, M. S., Chaudhry, A. H., Shafiq, M., \& Berhanu, G. (2011). Factors Affecting Students' Quality of Academic Performance: A Case of Secondary School Level.Journal of Quality and Technology Management, 7(2), 01-14. Retrieved from http://www.pu.edu.pk/images/journal/iqtm/PDF-FILES/01-Factor.pdf

Furnham, A., Monsen, J., \& Ahmetoglu, G. (2009). Typical intellectual engagement, Big Five personality traits, approaches to learning and cognitive ability predictors of academic performance. British Journal of Educational Psychology, 79(4), 769. doi:https://doi.org/10.1348/978185409X412147

Gottfried, A. W., Gottfried, A. E., Bathurst, K., Guerin, D. W., \& Parramore, M. M. (2003). Socioeconomic Status in Children's Development and Family Environment:Infancy Through Adolescence. In M. H. Bornstein \& R. H. Bradley (Eds.), Socioeconomic Status, Parenting, and Child Development (pp. 189-207). London: Lawrence Erlbaum Associates. 
Heilmann, K., Hinrichs, R., Herke, M., Richter, M., \& Rathmann, K. (2021). The Importance of the "Big Five" Personality Traits for Subjective Health and Life Satisfaction in Adolescence: Results of the National Educational Panel Study (NEPS)]. Gesundheitswesen, 83(1), 8-16. doi:10.1055/a-1068-2280

Hofstede, G. H., Hofstede, G. J., \& M, M. (2010). More Equal than Others. In G. H. Hofstede, G. J. Hofstede, \& M. M (Eds.), Cultures and Organizations: Software of The Mind: Intercultural Cooperation and its Importance for Survival (pp. 53-86). New York: McGraw-Hill.

Hughes, B. T., Costello, C. K., Pearman, J., Razavi, P., Bedford-Petersen, C., Ludwig, R. M., \& Srivastava, S. (2021). The Big Five Across Socioeconomic Status: Measurement Invariance, Relationships, and Age Trends (https://psyarxiv.com/wkhfx/). Retrieved from osf.io/wv59a

John, O. P., Naumann, L. P., \& Soto, C. J. (2008). Paradigm Shift to the Integrative Big Five Trait Taxonomy History, Measurement, and Conceptual Issues. In O. P. John, R. W. Robins, \& L. A. Pervin (Eds.), Handbook of Personality: Theory and Research(Third ed., pp. 114-158). New York: Guilford Press.

Johnson, J. A. (2014). Measuring thirty facets of the Five Factor Model with a 120-item public domain inventory: Development of the IPIP-NEO-120. Journal of Research in Personality, 51, 78-89. doi:https://doi.org/10.1016/j.jrp.2014.05.003

Jonassaint, C. R., Siegler, I. C., Barefoot, J. C., Edwards, C. L., \& Williams, R. B. (2011). Low life course socioeconomic status (SES) is associated with negative NEO PI-R personality patterns. International journal of behavioral medicine, 18(1), 13-21. doi:10.1007/s12529-0099069-x

Joshanloo, M., \& Afshari, S. (2011). Big Five Personality Traits and Self-Esteem as Predictors of Life Satisfaction in Iranian Muslim University Students. Journal of Happiness Studies, 12(1), 105113. doi:10.1007/s10902-009-9177-y

Kankaraš, M. (2017). Personality matters:Relevance and assessment of personality characteristics. Paris: Directorate for Education and Skills. Retrieved from https://www.oecdilibrary.org/docserver/8a294376-

en.pdf?expires $=1623138060 \& \mathrm{id}=\mathrm{id} \&$ accname $=$ guest $\&$ checksum $=2065258 \mathrm{C} 8$ AE0B74BB543 5FE44F5F1531

Kavirayani, K. (2018). Historical perspectives on personality - The past and current concept: The search is not yet over. Archives of Medicine and Health Sciences, 6(1), 180-186. doi: 10.4103/amhs.amhs_63_18

Komarraju, M., Karau, S. J., Schmeck, R. R., \& Avdic, A. (2011). The Big Five personality traits, learning styles, and academic achievement. Personality and Individual Differences, 51(4), 472-477. doi:http://dx.doi.org/10.1016/j.paid.2011.04.019

Maltby, J., Day, L., \& Macaskill, A. (2017). Personality Theory in Context. In M. John, D. Liz, \& M. Ann (Eds.), Personality, individual differences and intelligence (Fourth Edition ed.). United Kingdom: Pearson Education.

McCrae, R. R., \& Costa, P. T. (2008). The Five-F actor Theory of Personality. In O. P. John, R. W. Robins, \& L. A. Pervin (Eds.), Handbook of personality: Theory and research (Third ed., pp. 159-181). New York: Guilford Press.

Poropat, A. E. (2009). A meta-analysis of the five-factor model of personality and academic performance. Psychological Bulletin, 135(2), 322-338. doi:10.1037/a0014996

Rolfhus, E. L., \& Ackerman, P. L. (1999). Assessing individual differences in knowledge: Knowledge, intelligence, and related traits. Journal of Educational Psychology, 91(3), 511526. doi:10.1037/0022-0663.91.3.511

Rosander, P., \& Bäckström, M. (2012). The unique contribution of learning approaches to academic performance, after controlling for IQ and personality: Are there gender differences? Learning and Individual Differences, 22(6), 820-826. doi:http://dx.doi.org/10.1016/j.lindif.2012.05.011

Rothstein, R. (2010). Family Environment in the Production of Schooling. In P. Penelope, B. Eva, \& M. Barry (Eds.), International Encyclopedia of Education(03 ed., Vol. 02). Oxford: Academic Press, Elsevier.

Sackett, P. R., \& Walmsley, P. T. (2014). Which Personality Attributes Are Most Important in the Workplace? Perspectives on Psychological Science, 9(5), 538-551. doi:10.1177/1745691614543972 
Sharma, R. (2017). Update: Revised Kuppuswamy's Socioeconomic Status Scale: Explained and Updated. Indian Pediatrics, $\quad$ 54(15), doi:https://www.indianpediatrics.net/oct2017/867.pdf

Sirin, S. R. (2005). Socioeconomic Status and Academic Achievement: A Meta-Analytic Review of Research. Review of Educational Research, 75(3), 417-453. doi:10.3102/00346543075003417

Soto, C. J. (2018). Big Five personality traits. In M. H. Bornstein, M. E. Arterberry, K. L. Fingerman, \& J. E. Lansford (Eds.), The SAGE Encyclopedia of Lifespan Human Development (pp. 240241). Thousand Oaks, CA: Sage.

Strickhouser, J. E., \& Sutin, A. R. (2020). Family and neighborhood socioeconomic status and temperament development from childhood to adolescence. Journal of Personality, 88(3), 515529. doi:https://doi.org/10.1111/jopy.12507

Vazire, S. (2014). Personality: A Six-Day Unit Lesson Plan for High School Psychology Teachers: Developed and Produced by the Teachers of Psychology in Secondary Schools (TOPSS) of the American Psychological Association, December 2014. Retrieved from https://www.apa.org/ed/precollege/topss/lessons/personality.pdf

Vermetten, Y. J., Lodewijks, H. G., \& Vermunt, J. D. (2001). The Role of Personality Traits and Goal Orientations in Strategy Use. Contemporary Educational Psychology, 26(2), 149-170. doi:http://dx.doi.org/10.1006/ceps.1999.1042

Yang, Y., \& Gustafsson, J.-E. (2004). Measuring Socioeconomic Status at Individual and Collective Levels. Educational Research and Evaluation, 10(3), 259-288. doi:10.1076/edre.10.3.259.30268

Yuxiao, W., \& Chao, H. (2017). School Socioeconomic Segregation and Educational Expectations of Students in China's Junior High Schools, Social Sciences in China. Social Sciences in China, 38(3), 112-126. doi:10.1080/02529203.2017.1339449

Zuffianò, A., Alessandri, G., Gerbino, M., Luengo Kanacri, B. P., Di Giunta, L., Milioni, M., \& Caprara, G. V. (2013). Academic achievement: The unique contribution of self-efficacy beliefs in self-regulated learning beyond intelligence, personality traits, and self-esteem. Learning and Individual Differences, 23(0), 158-162. doi:http://dx.doi.org/10.1016/j.lindif.2012.07.010 